Acta Crystallographica Section E

Structure Reports

Online

ISSN 1600-5368

Editors: W. Clegg and D. G. Watson

\title{
Benzyltributylammonium 4-hydroxynaphthalene-1-sulfonate
}

Jin Mizuguchi, Yohei Sato, Kazuya Uta and Kazuyuki Sato

Copyright $($ International Union of Crystallography

Author(s) of this paper may load this reprint on their own web site provided that this cover page is retained. Republication of this article or its storage in electronic databases or the like is not permitted without prior permission in writing from the IUCr. 
Acta Crystallographica Section E

Structure Reports

Online

ISSN 1600-5368

\section{Jin Mizuguchi,* Yohei Sato, Kazuya Uta and Kazuyuki Sato}

Department of Applied Physics, Graduate School of Engineering, Yokohama National University, Tokiwadai 79-5, Hodogaya-ku, Yokohama 240-8501, Japan

Correspondence e-mail: mizu-j@ynu.ac.jp

\section{Key indicators}

Single-crystal X-ray study $T=296 \mathrm{~K}$

Mean $\sigma(\mathrm{C}-\mathrm{C})=0.004 \AA$

Some non- $\mathrm{H}$ atoms missing

Disorder in main residue

$R$ factor $=0.049$

$w R$ factor $=0.162$

Data-to-parameter ratio $=14.1$

For details of how these key indicators were automatically derived from the article, see http://journals.iucr.org/e.

\section{Benzyltributylammonium 4-hydroxy- naphthalene-1-sulfonate}

The title compound, $\mathrm{C}_{19} \mathrm{H}_{34} \mathrm{~N}^{+} \cdot \mathrm{C}_{10} \mathrm{H}_{7} \mathrm{O}_{4} \mathrm{~S}^{-}$, is a charge-control agent used in electrophotography. The anions form chains Received 30 December 2006 along the $b$ axis through $\mathrm{O}-\mathrm{H} \cdots \mathrm{O}$ hydrogen bonding.

\section{Comment}

The title compound, (I), is an ammonium salt used widely as a charge-control agent (CCA) of the positive type for toners in electrophotography (Tanaka, 1995). CCAs are usually added to toners to create a desired charge level and polarity (Nash et al., 2001). However, the charge-control mechanism of CCA is not fully understood at the moment. We have, therefore, determined the title crystal structure as a step to elucidating the mechanism.

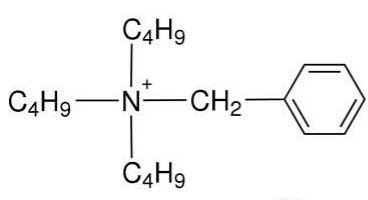<smiles>O=S(=O)([O-])c1ccc(O)c2ccccc12</smiles>

(I)

Fig. 1 shows the asymmetric unit of (I). The ions have no crystallographically imposed symmetry. Fig. 2 shows a hydrogen-bonded chain along the $b$ axis, formed by $\mathrm{O}-$ H. . O hydrogen bonding (Table 1).

\section{Experimental}

Compound (I) was obtained from Orient Chemical Industries Ltd, and was recrystallized from a methanol solution. After $48 \mathrm{~h}$, a number of colorless crystals were obtained in the form of blocks.

Crystal data

$\begin{array}{ll}\mathrm{C}_{19} \mathrm{H}_{34} \mathrm{~N}^{+} \cdot \mathrm{C}_{10} \mathrm{H}_{7} \mathrm{O}_{4} \mathrm{~S}^{-} & V=2787.8(4) \AA^{3} \\ M_{r}=499.70 & Z=4 \\ \text { Monoclinic, } P 2_{1} / n & \mathrm{Cu} K \alpha \text { radiation } \\ a=14.3810(11) \AA & \mu=1.29 \mathrm{~mm}^{-1} \\ b=9.8124(7) \AA & T=296.1 \mathrm{~K} \\ c=19.7757(15) \AA & 0.20 \times 0.20 \times 0.20 \mathrm{~mm}\end{array}$

$$
\beta=92.560(5)^{\circ}
$$

\section{Data collection}

Rigaku R-AXIS RAPID diffractometer

Absorption correction: multi-scan (ABSCOR; Higashi, 1995) $T_{\min }=0.745, T_{\max }=0.772$

\section{Refinement}

$R\left[F^{2}>2 \sigma\left(F^{2}\right)\right]=0.049$

$w R\left(F^{2}\right)=0.162$

$S=1.19$

4902 reflections
Accepted 9 April 2007
24226 measured reflections 4902 independent reflections 3490 reflections with $F^{2}>2 \sigma\left(F^{2}\right)$ $R_{\text {int }}=0.036$

347 parameters

$\mathrm{H}$-atom parameters constrained

$\Delta \rho_{\max }=0.45{\mathrm{e} \AA^{-3}}^{-3}$

$\Delta \rho_{\min }=-0.24{\mathrm{e} \AA^{-3}}^{-3}$ 


\section{organic papers}

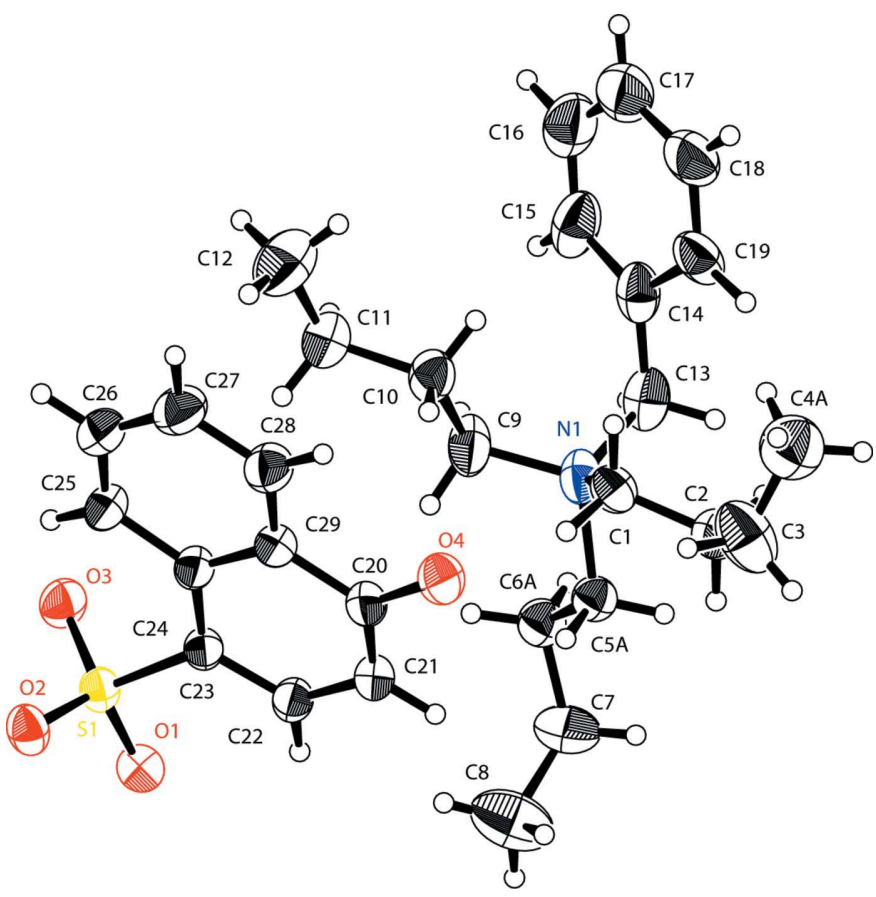

Figure 1

The asymmetric unit of (I), showing $30 \%$ probability displacement ellipsoids and only the major disorder components.

Table 1

Hydrogen-bond geometry $\left(\AA{ }^{\circ}\right)$.

\begin{tabular}{lllll}
\hline$D-\mathrm{H} \cdots A$ & $D-\mathrm{H}$ & $\mathrm{H} \cdots A$ & $D \cdots A$ & $D-\mathrm{H} \cdots A$ \\
\hline $\mathrm{O} 4-\mathrm{H} 4 \cdots \mathrm{O} 1^{\mathrm{i}}$ & 0.82 & 1.85 & $2.657(2)$ & 169 \\
\hline
\end{tabular}

Symmetry code: (i) $-x+\frac{1}{2}, y+\frac{1}{2},-z+\frac{1}{2}$.

C4, C5 and C6 were found to be disordered over two sites each. The site occupancies for $\mathrm{C} 4 A / \mathrm{C} 4 B$ are 0.742 (7):0.258 (7), whereas those for for $C 5 A / C 5 B$ and $C 6 A / C 6 B$ are 0.460 (6):0.540 (6). These atoms were isotropically refined. All $\mathrm{H}$ atoms were placed in geometrically idealized positions and constrained to ride on their parent atoms, with $\mathrm{C}-\mathrm{H}=0.93 \AA$ (aromatic), $0.96 \AA$ (methyl) or $0.97 \AA$ (methylene), and $\mathrm{O}-\mathrm{H}=0.82 \AA ; U_{\text {iso }}(\mathrm{H})=1.2 U_{\text {eq }}$ (parent atom).

Data collection: PROCESS-AUTO (Rigaku, 1998); cell refinement: PROCESS-AUTO; data reduction: CrystalStructure (Rigaku/ MSC, 2006); program(s) used to solve structure: SIR2004 (Burla et al.,

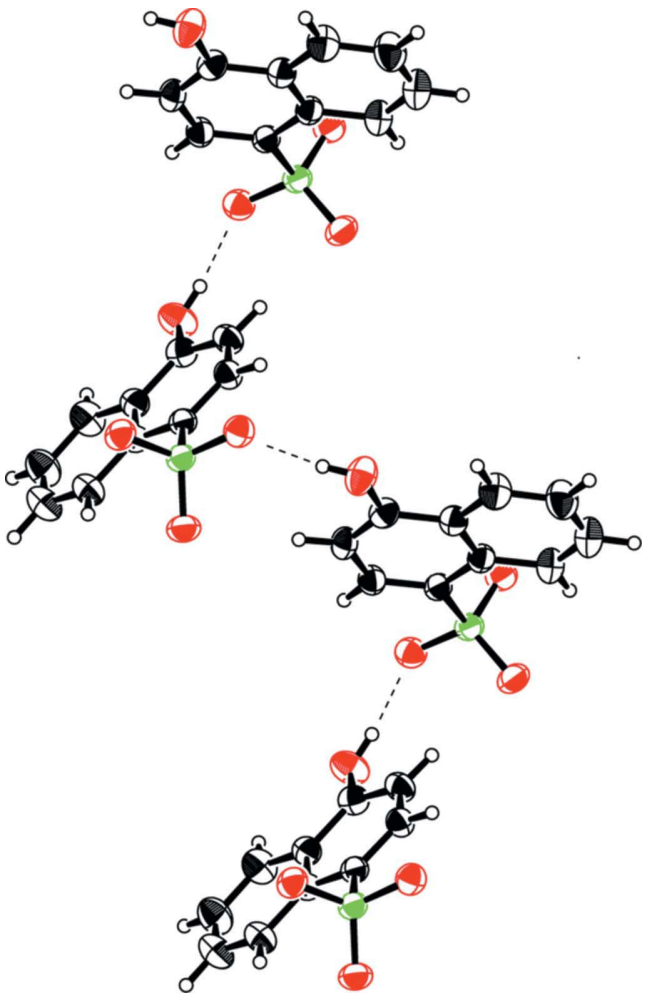

Figure 2

The formation of a hydrogen-bonded (dashed lines) chain.

2003); program(s) used to refine structure: SHELXL97 (Sheldrick, 1997); molecular graphics: ORTEPIII (Burnett \& Johnson, 1996); software used to prepare material for publication: CrystalStructure.

\section{References}

Burla, M. C., Camalli, M., Carrozzini, B., Cascarano, G. L., Giacovazzo, C., Polidori, G. \& Spagna, R. (2003). J. Appl. Cryst. 36, 1103.

Burnett, M. N. \& Johnson, C. K. (1996). ORTEPIII. Report ORNL-6895. Oak Ridge National Laboratory, Tennessee, USA.

Higashi, T. (1995). ABSCOR. Rigaku Corporation, Tokyo, Japan.

Nash, R. J., Grande, M. L. \& Muller, R. N. (2001). Proceedings of the 17th International Conference on Advances in Non-Impact Printing Technology, pp. 358-364. Springfield, Virginia: Society for Imaging Science and Technology.

Rigaku (1998). PROCESS-AUTO. Rigaku Corporation, Tokyo, Japan. Rigaku/MSC (2006). CrystalStructure. Version 3.8. Rigaku/MSC, The Woodlands, Texas, USA.

Sheldrick, G. M. (1997). SHELXL97. University of Göttingen, Germany. Tanaka, K. (1995). Proc. Inst. Electrost. Jpn, 19, 15-21. 